\title{
Effect of smoking on acute phase reactants, stress hormone responses and vitamin $C$ in pulmonary tuberculosis.
}

\author{
John O Opolot, ${ }^{1}$ Annette J Theron, ${ }^{2,3}$ Patrick MacPhail, ${ }^{4}$ Charles Feldman, ${ }^{1}$ Ronald Anderson ${ }^{2}$
}

1. Division of Pulmonology, Department of Internal Medicine, Charlotte Maxeke Johannesburg Academic Hospital and Faculty of Health Sciences, University of the Witwatersrand, Johannesburg, South Africa

2. Department of Immunology, Faculty of Health Sciences, University of Pretoria, Pretoria, South Africa

3. Tshwane Academic Division of the National Health Laboratory Service, Pretoria, South Africa

4. Division of Haematology/Oncology, Department of Internal Medicine, Charlotte Maxeke Johannesburg Academic Hospital and Faculty of Health Sciences, University of the Witwatersrand, Johannesburg, South Africa

\begin{abstract}
Background: Chronic inflammation, possibly exacerbated by cigarette smoking, is considered to be the primary cause of pulmonary damage in patients with tuberculosis (TB). However, the mechanisms which underpin these harmful inflammatory responses, have not been well documented.

Objectives: The current study was undertaken to determine possible associations between systemic biomarkers of inflammation (acute phase reactants, stress hormones, leukocyte vitamin C) and smoking status in patients ( $\mathrm{n}=71,20$ smokers) with newly-diagnosed pulmonary TB presenting at a tertiary hospital, Johannesburg, South Africa.

Methods: Plasma concentrations of C-reactive protein (CRP), ferritin, cortisol, epinephrine, norepinephrine, dopamine and leukocyte vitamin $\mathrm{C}$ were measured using a combination of immunonephelometric, radioimmunoassay, immunochromatographic and spectrophotometric procedures. Demographic, clinical and laboratory data was captured and analysed by parametric and non-parametric analyses where appropriate.

Results: Smokers were predominantly males $(\mathrm{P}<0.0001)$, of older age $(\mathrm{P}<0.0003)$ with a significantly lower body mass index $(\mathrm{P}<0.03)$. Plasma levels of CRP, ferritin and dopamine were higher in the group of smokers in the setting of lower levels of epinephrine, and leukocyte vitamin $\mathrm{C}$, with $\mathrm{CRP}$ and vitamin $\mathrm{C}$ attaining statistical significance $(\mathrm{P}<0.04$ and $\mathrm{P}<0.02$ respectively). Those of cortisol and norepinephrine were comparable to those of non-smokers, as were radiographic changes and clinical indices of disease activity.

Conclusion: Cigarette smoking is associated with an exaggerated systemic inflammatory response in pulmonary TB in the setting of decreased concentrations of leukocyte vitamin C. Although no significant associations with radiographic changes and most clinical indices of disease activity were evident on presentation, these pro-inflammatory interactions may have prognostic significance.
\end{abstract}

Keywords: Catecholamines, C-reactive protein, ferritin, Mycobacterium tuberculosis, leukocyte vitamin C.

DOI: https://dx.doi.org/10.4314/ahs.v17i2.7

Cite as: Opolot JO, Theron AJ, MacPhail P, Feldman C, Anderson R. Effect of smoking on acute phase reactants, stress hormone responses and vitamin C in pulmonary tuberculosis. Afri Health Sci. 2017;17(2):337-345. bttps:// dx.doi.org/10.4314/abs.v17i2.7
Corresponding author:
Ronald Anderson,
Department of Immunology,
Institute of Pathology,
P. O. Box 2034,
Pretoria, South Africa,
Tel: +27-12-319-2425,
Fax: +27-12-323-0732,
Email: ronald.anderson@up.ac.za

\section{Background}

Cigarette smoking is not only a risk factor for the development of pulmonary tuberculosis $(\mathrm{TB})^{1,2}$, but has also been reported to delay sputum conversion prolonging infectivity, to counteract the efficacy of anti-microbial chemotherapy, and increase the risk of recurrence following successful therapy ${ }^{2,3}$. Although the harmful effects of smoking on predisposition for development of TB are primarily attributed to interference with pulmonary host defences, pathogen-targeted mechanisms may also contribute $^{2}$. These include smoke-activated induction of 
biofilm formation by respiratory pathogens ${ }^{2,4}$, and promotion of gene modifications in microbial nucleic which may lead to antibiotic resistance ${ }^{5}$. Notwithstanding interference with pulmonary host defences, cigarette smoking also causes a chronic, low-grade systemic inflammatory response, resulting in the sustained influx of neutrophils and monocytes into the lungs ${ }^{2}$, potentially intensifying harmful inflammatory responses and pulmonary dysfunction ${ }^{6}$.

Cigarette smoking and TB per se are also associated with altered vitamin $\mathrm{C}$ status due to both decreased intake and increased utilisation of the vitamin ${ }^{7-9}$, presenting a potential risk for increased susceptibility to TB, as well as disease severity. This contention is supported by several recent studies describing the selective anti-mycobacterial actions of vitamin $\mathrm{C}$, either bactericidal or bacteriostatic, depending on the concentration of the vitamin and availability of iron ${ }^{10-12}$. In addition, vitamin $C$ which is stored in the adrenal gland, is also required for synthesis of catecholamines ${ }^{13}$, a component of the endogenous anti-inflammatory stress hormone response, which may ameliorate pulmonary damage and dysfunction in $\mathrm{TB}^{14-}$ 16. However, the possible relationships between cigarette smoking, vitamin $\mathrm{C}$ status, and the acute phase and stress hormone responses in patients with pulmonary TB have not been well characterised.

This issue has been addressed in the current study in which a range of circulating markers of inflammatory activity (acute phase reactants, stress hormones) and oxidative stress (vitamin C) have been measured and compared with clinical and radiographic indices of disease activity in newly-diagnosed, hospitalised patients with pulmonary TB in relation to smoking history. This is a component of a larger study focused on the acute and stress hormone responses in patients with pulmonary $\mathrm{TB}^{17}$.

\section{Patients and methods}

The study was approved by the Committee for Research on Human Subjects of the University of the Witwatersrand (Protocol no.: MO1-11-14). Prior written informed consent was obtained from all patients.

\section{Patients}

Seventy one newly-diagnosed, treatment-naïve patients with pulmonary TB admitted to Helen Joseph Hospital,
Johannesburg were recruited in the study. All patients were $\geq 18$ years of age and TB was confirmed clinically, radiologically and microbiologically. Exclusion criteria included previous TB infection and/or treatment, co-morbid illness (diabetes mellitus, cardiomyopathy, renal failure, malignancy), those with concomitant immuno-suppression due to causes other than HIV infection, and those with AIDS-defining illnesses other than TB, as well as patients on highly- active anti-retroviral therapy. All of the patients presented with new-onset respiratory symptoms to an emergency department where they were considered by the emergency clinician to require hospitalisation for further investigation and management. There was no previous history of TB or anti-mycobacterial drug resistance. With respect to estimation of length of illness prior to hospitalisation, the mean durations of the longest symptom for the groups of non-smokers and smokers were 6.8 and 8.6 weeks respectively (not significantly different). Twenty five patients (11 females and 14 males, 2 and 5 of whom were smokers respectively) were HIV-seropositive, while the HIV-status of the remainder was unknown. To minimise the influence of diurnal variation, blood specimens were taken between 0800 and 0900 hours following an 8 hour overnight fast, processed promptly as required for the various specialised investigations described below and stored at $-70^{\circ} \mathrm{C}$ until assayed. Following venopuncture, patients diagnosed with pulmonary TB were treated with standard antibiotics.

\section{Demographic and clinical data}

Demographic data included age, gender, ethnicity, and smoking history, while clinical examination recorded blood pressure, pulse rate, body temperature, body height and weight, and body mass index (BMI, $\mathrm{kg} / \mathrm{m}^{2}$ ). Weight loss was recorded on a "self-reporting" basis as being mild, moderate or severe. Patients were categorised as smokers on the basis of a history of active smoking within the preceding 3 months.

\section{Chest radiography}

Abnormalities on chest radiographs were recorded and included cavitation, nodules/nodular infiltration, nodes/ hilar fullness, effusions, consolidation, and volume loss.

\section{Laboratory investigations}

Plasma levels of C-reactive protein (CRP) and ferritin were measured using an immunonephelometric (Behring 
Diagnostics, Marburg, Germany) and a sandwich ELISA procedure (Technicon Immuno-1 System, Miles Inc., Diagnostic Division, Tarrytown, NY, USA) respectively, with the respective results recorded as micrograms $(\mu \mathrm{g})$ per millilitre $(\mathrm{mL})$ and nanograms $(\mathrm{ng}) / \mathrm{mL}$. The normal ranges for these acute phase reactants are $<5 \mu \mathrm{g} /$ $\mathrm{mL}$ for CRP, and, in the case of ferritin, $10-150 \mathrm{ng} / \mathrm{mL}$ and $12-300 \mathrm{ng} / \mathrm{mL}$ for females and males respectively. Concentrations of plasma cortisol were measured by radioimmunoassay, while those of the catecholamines(epinephrine, norepinephrine, dopamine) were determined by a high-performance liquid chromatographic procedure (Bio-Rad Laboratories Diagnostic Group, CA, USA) with results for cortisol expressed as nanomoles (nmol)/L, and those of the other 3 analytes as picomoles (pmol)/L. The normal ranges for each of these are 119-618 nmo1/L (cortisol), 0-366 pmol/L, (epinephrine), 560-2636 $\mathrm{pmol} / \mathrm{L}$ (norepinephrine), and $0-890 \mathrm{pmol} / \mathrm{L}$ (dopamine). Following extraction, leukocyte vitamin $\mathrm{C}$ concentrations were measured using a 2,4-dinitrophenylhydrazine-based spectrophotometric procedure, with results expressed as $\mu \mathrm{g} / 10^{8}$ cells. The mean value for leukocyte vitamin $C$ for healthy control subjects for our study population is $26 \pm 11.2$ and $30.7 \pm 11.9 \mu \mathrm{g} / 10^{8}$ cells for females and males respectively ${ }^{18}$.

Additional investigations included measurement of circulating total leukocyte count, platelets, haemoglobin and mean corpuscular volume, as well as urea and creatinine using standard haematological and blood chemistry procedures.

\section{Statistical analysis}

Demographic, clinical and laboratory data were analysed using SPSS 7.5 and/or Graphpad Instat software. For evaluation of continuous variables, normality tests were performed to determine normality of distribution of data with analysis thereafter using the unpaired (2-tailed) student's $t$ test or the Mann-Whitney u-test for normally and non-normally distributed data respectively. The results are presented as the mean values for each parameter \pm the standard deviation (SD) and/or 95\% confidence intervals (CIs), together with relative risk values where appropriate. Log transformation of the ferritin and leukocyte vitamin C data was also undertaken, but had no influence on the statistical analyses. For analysis of categorical variables, the Fisher's exact test (2-tailed) was performed.

\section{Results}

\section{Demographic and clinical data of patients catego- rized according to smoking status}

These are shown in Tables 1 and 2. The patient cohort consisted of 51 non-smokers and 20 smokers based on smoking history, with the smokers being predominantly of male gender $(\mathrm{P}<0.0001)$, as described previously for this study group ${ }^{7,19}$, as well as being significantly older than the non-smokers $(\mathrm{P}<0.0003)$. 

Table 1: Demographic and clinical profiles of the cohort of patients with pulmonary
tuberculosis classified according to smoking status

\begin{tabular}{|c|c|c|c|c|c|c|c|}
\hline \multirow[b]{2}{*}{ Gender } & \multicolumn{3}{|c|}{ Non-smokers $(n=51)$} & \multicolumn{3}{|c|}{ Smokers $(n=20)$} & \multirow{2}{*}{$\begin{array}{l}\boldsymbol{P} \text { value } \\
0.0001\end{array}$} \\
\hline & \multicolumn{2}{|c|}{31 Female } & 20 Male & \multicolumn{2}{|c|}{2 Female } & 18 Male & \\
\hline \multirow[t]{2}{*}{ Ethnicity } & \multicolumn{2}{|c|}{49 Black } & 2 Mixed Race & \multicolumn{2}{|c|}{14 Black } & $\begin{array}{l}6 \text { Mixed } \\
\text { Race }\end{array}$ & 0.24 \\
\hline & mean & $\pm S D$ & $95 \% \mathrm{Cl}$ & mean & $\pm S D$ & $95 \% \mathrm{Cl}$ & \\
\hline Age (years) & 32.8 & 8.0 & $30.565-35.82$ & 41.5 & 10.1 & $36.703-46.197$ & 0.0003 \\
\hline $\begin{array}{l}\text { Body mass index } \\
\left(\mathrm{kg} / \mathrm{m}^{2}\right)\end{array}$ & 18.86 & 4.1 & $17.701-20.016$ & 16.87 & 2.5 & $15.696-8.036$ & 0.03 \\
\hline $\begin{array}{l}\text { Blood pressure systolic } \\
(\mathrm{mmHg})\end{array}$ & 103 & 10 & $100.52-106.15$ & 102.6 & 10.4 & $97.752-107.45$ & 0.21 \\
\hline $\begin{array}{l}\text { Blood pressure } \\
\text { diastolic }(\mathrm{mmHg})\end{array}$ & 65.3 & 9.5 & $62.576-67.934$ & 66.4 & 9.5 & $61.951-70.849$ & 0.74 \\
\hline Pulse (beats/min) & 101.6 & 16.7 & $96.877-106.30$ & 102.6 & 10.4 & $97.752-107.45$ & 0.80 \\
\hline \multirow[t]{2}{*}{ Body temperature $\left({ }^{\circ} \mathrm{C}\right)$} & 38.68 & 0.73 & $38.386-38.864$ & 38.63 & 0.51 & $38.474-38.896$ & 0.75 \\
\hline & & $\mathrm{n}$ & $\%$ & \multicolumn{2}{|c|}{$\mathrm{n}$} & $\%$ & \\
\hline Lymphadenopathy & & 25 & 49 & \multicolumn{2}{|c|}{10} & 50 & 1.00 \\
\hline Chest dullness & & 36 & 71 & \multicolumn{2}{|c|}{17} & 85 & 0.235 \\
\hline Crackles & & 50 & 98 & \multicolumn{2}{|c|}{20} & 100 & 1.00 \\
\hline Bronchial breathing & & 10 & 20 & \multicolumn{2}{|c|}{4} & 20 & 1.00 \\
\hline
\end{tabular}

Body mass index also differed between the 2 groups, being significantly lower in the group of smokers $(\mathrm{P}<0.03)$, while self-reporting of weight loss revealed a tendency, albeit not achieving statistical significance, towards a greater degree of weight loss in the group of smokers $(\mathrm{P}=0.052)$.
Radiographic data

Radiographic data is shown in Table 2. No differences between the groups of smokers and non-smokers were evident. 
Table 2: Chest X-ray findings in non-smokers $(n=51)$ and smokers $(n=20)$ with pulmonary tuberculosis

\begin{tabular}{llllll}
\hline & $\begin{array}{l}\text { Non- } \\
\text { smokers (n) }\end{array}$ & $\begin{array}{l}\text { Smoker } \\
\mathbf{s}(\mathbf{n})\end{array}$ & $\mathbf{R R}$ & $\mathbf{9 5 \%} \mathbf{C l}$ & $\mathbf{P}$ value \\
\hline $\begin{array}{l}\text { Nodular infiltrate / } \\
\text { nodules }\end{array}$ & 36 & 15 & 0.94 & 0.6910 & 1.282 \\
$\begin{array}{l}\text { Nodes /hilar } \\
\text { fullness }\end{array}$ & 35 & 14 & 0.98 & 0.7194 & 1.341 \\
Consolidation & 32 & 11 & 1.10 & 0.8048 & 1.494 \\
Cavitation & 29 & 13 & 0.91 & 0.6821 & 1.214 \\
Effusions & 8 & 5 & 0.83 & 0.5261 & 1.310 \\
Volume loss & 7 & 3 & 0.97 & 0.6283 & 1.499 \\
\hline
\end{tabular}

\section{Laboratory investigations}

The results of the various laboratory measurements are shown in Table 3. Concentrations of circulating CRP and ferritin were higher in the group of smokers, achieving statistical significance in the case of CRP $(\mathrm{P}<0.04)$. Mean plasma concentrations of cortisol were comparable and within the normal range for both groups, while epinephrine and norepinephrine levels were close to the upper limit of normal or slightly above, with epinephrine being lower and dopamine higher in the group of smokers, although not significantly so. Leukocyte vitamin $\mathrm{C}$ was significantly lower in the group of smokers $(\mathrm{P}<0.02)$, while the value for non-smokers was within the normal range. With respect to haematological and blood chemistry indices, no statistically significant differences were evident between the 2 groups (data for the other parameters is not shown). 


\section{Table 3: Acute phase reactants, leukocyte vitamin $\mathrm{C}$ and stress hormones in non-smokers and smokers with pulmonary TB.}

\begin{tabular}{|c|c|c|c|c|c|c|c|}
\hline \multirow{2}{*}{ Variables } & \multicolumn{3}{|c|}{ Non-smokers } & \multicolumn{3}{|c|}{ Smokers } & \multirow{2}{*}{$P$ Value } \\
\hline & mean & SD & $95 \% \mathrm{Cl}$ & mean & SD & $95 \% \mathrm{Cl}$ & \\
\hline $\mathrm{CRP}(\mu \mathrm{g} / \mathrm{mL})$ & $\begin{array}{l}118 \\
(n=51)\end{array}$ & 50 & $\begin{array}{l}103.74 \\
131.67\end{array}$ & $\begin{array}{l}147 \\
(n=20)\end{array}$ & 63 & $\begin{array}{l}117.53 \\
176.21\end{array}$ & 0.04 \\
\hline Ferritin (ng/mL) & $\begin{array}{l}2443 \\
(n=51)\end{array}$ & 4170 & $\begin{array}{l}1329.1 \\
7551.2\end{array}$ & $\begin{array}{l}4440 \\
(n=20)\end{array}$ & 6647 & $\begin{array}{l}1269.4 \\
3617.4\end{array}$ & 0.15 \\
\hline $\begin{array}{l}\text { White cell } \\
\text { vitamin } C \\
\left(\mu g / 10^{8} \text { cells }\right)\end{array}$ & $\begin{array}{l}35 \\
(n=50)\end{array}$ & 32 & $\begin{array}{l}25.514 \\
43.811\end{array}$ & $\begin{array}{l}17 \\
(n=20)\end{array}$ & 11 & $\begin{array}{l}11.501 \\
21.569\end{array}$ & 0.02 \\
\hline Cortisol (nmol/L) & $\begin{array}{l}436 \\
(n=49)\end{array}$ & 192 & $\begin{array}{l}380.6 \\
490.78\end{array}$ & $\begin{array}{l}458 \\
(n=19)\end{array}$ & 233 & $\begin{array}{l}345.16 \\
570.10\end{array}$ & 0.69 \\
\hline $\begin{array}{l}\text { Epinephrine } \\
\text { (pmol/L) }\end{array}$ & $\begin{array}{l}480 \\
(n=41)\end{array}$ & 415 & $\begin{array}{l}348.87 \\
610.98\end{array}$ & $\begin{array}{l}399 \\
(n=16)\end{array}$ & 265 & $\begin{array}{l}257.94 \\
540.68\end{array}$ & 0.70 \\
\hline $\begin{array}{l}\text { Norepinephrine } \\
(\mathrm{pmol} / \mathrm{L})\end{array}$ & $\begin{array}{l}2520 \\
(n=41)\end{array}$ & 2041 & $\begin{array}{l}1875.6 \\
3163.8\end{array}$ & $\begin{array}{l}2562 \\
(n=16)\end{array}$ & 2118 & $\begin{array}{l}1433.9 \\
3690.3\end{array}$ & 0.95 \\
\hline $\begin{array}{l}\text { Dopamine } \\
(\mathrm{pmol} / \mathrm{L})\end{array}$ & $\begin{array}{l}421 \\
(n=41)\end{array}$ & 328 & $\begin{array}{l}317.93 \\
524.35\end{array}$ & $\begin{array}{l}589 \\
(n=16)\end{array}$ & 474 & $\begin{array}{l}336.59 \\
841.16\end{array}$ & 0.33 \\
\hline
\end{tabular}

\section{Discussion}

In agreement with previous studies, the findings of the current study have documented that patients with pulmonary TB have relatively high levels of the anti-inflammatory stress hormones epinephrine and norepinephrine in the setting of an intense inflammatory response reflected by high concentrations of the acute phase reactants, CRP and ferritin ${ }^{7,14-16}$. When the patients were categorised according to smoking status, differences emerged with respect to the magnitude of the acute phase response and its relationship with stress hormones, as well as with leukocyte vitamin C. Cigarette smoking was found to be associated with higher concentrations of circulating CRP and ferritin in the setting of decreased concentrations of leukocyte vitamin $\mathrm{C}$, and a decrease, albeit not attaining statistical significance, in the concentration of the anti-inflammatory stress hormone, epinephrine, but not cortisol. The observed increase in CRP levels, in the group of smokers with TB was not detected in a previous study ${ }^{7}$, possibly due to differences in disease severity between the different patient cohorts. In this context, it is noteworthy that the magnitude of the CRP response has recently been reported to reflect the mycobacterial load in patients with $\mathrm{TB}^{20}$.
It is noteworthy that the group of smokers, which consisted predominantly of males as previously reported for this study population ${ }^{7}$, was significantly older with lower BMIs than the group of non-smokers. These findings of the current study are consistent with a relationship between older age, male gender, smoking, and under-nutrition/hypovitaminosis C. The apparent exacerbation of the inflammatory response in smokers observed in the current study was not, however, associated with significant differences in radiographic and other clinical indices of disease activity. The failure to detect possible differences may be due to the relatively small numbers of subjects in each group, as well as to overall disease severity. Nevertheless, alterations in the concentrations of the various measured systemic markers of inflammation provide plausible support for a potentially harmful pro-inflammatory interaction between pulmonary TB and smoking.

Vitamin C has been reported to possess bactericidal activity against both $M$. bovis ${ }^{11}$ and $M$. tuberculosis ${ }^{12}$. In the latter study, a sterilizing action on $M$. tuberculosis was observed at a vitamin $C$ concentration of 4 millimolar ( $\mathrm{mM}$ ) which was dependent on the presence of ferrous iron, leading to the generation of anti-microbial hydroxyl radical. Importantly, intracellular concentrations of vitamin 
$\mathrm{C}$ in activated monocytes and macrophages have been reported to be $\geq 14 \mathrm{mM}^{21}$. The emerging role of vitamin $\mathrm{C}$ in host defence against $M$. tuberculosis, mediated via its pro-oxidative interactions with ferrous iron ${ }^{10-12}$, may implicate the involvement of ferritin as an intracellular iron donor. Although generally believed to reinforce anti-oxidative host defences via sequestration of iron, delivery of iron to $M$. tuberculosis-infected macrophages represents an alternative, albeit pro-oxidative, protective activity of ferritin ${ }^{22}$. In this context, it is noteworthy that other acute phase reactants have been reported to possess seemingly counteracting pro- and anti-inflammatory activities, which are likely to be operative at different stages of inflammatory responses. For example, CRP possesses both opsonic and complement-activating properties ${ }^{23,24}$, while this acute phase reactant and peptides derived from it have been reported to suppress neutrophil and T lymphocyte activation respectively ${ }^{25,26}$.

The association of cigarette smoking, oxidative stress and depletion of vitamin $\mathrm{C}$ is well recognised, with leukocyte vitamin $\mathrm{C}$ considered to be representative of tissue concentrations of the vitamin ${ }^{8,9}$. In addition, vitamin $\mathrm{C}$, which is stored in the adrenal gland, is not only required for synthesis of catecholamines, but is also secreted in response to adrenocorticotrophic hormone, presumably as an endogenous anti-oxidative, anti-inflammatory defence mechanism ${ }^{13}$. The findings of the current study suggest that TB and smoking have an interactive effect on depletion of tissue stores of vitamin C. This, in turn, may lead to decreased efficacy of the anti-inflammatory stress hormone response, specifically production of epinephrine, and an accompanying predisposition to inflammation-mediated pulmonary damage. This contention is supported by the finding of higher levels of dopamine, a precursor of epinephrine, in the group of smokers.

Notwithstanding relatively small numbers of patients as mentioned above, potential limitations of our study include the absence of detectable differences in the extent of lung cavitation between smokers and non-smokers, as well as follow-up studies during treatment to monitor the time-course of culture conversion between the two groups. In the case of the former, however, differences in cavitation, which is largely immune-mediated, may be difficult to detect due to smoking-related pulmonary immune dysfunction; irrespective of this caveat, a pre- vious study involving 13,088 cases of pulmonary TB has, however, documented more severe cavitary disease in smokers ${ }^{6}$. With respect to culture conversion, delayed sputum conversion in smokers has also been reported in several studies ${ }^{27-29}$. Follow-up studies may also identify the relative contributions of infection and smoking to the observed alterations in vitamin $\mathrm{C}$ status. Additional limitations include the lack of a healthy control group, although we believe that this limitation is largely negated by the inclusion of well-established normal ranges for the various investigations. Moreover, the primary objective of this study was to assess the effects of smoking on indices of inflammation and vitamin $\mathrm{C}$ status in patients with primary $\mathrm{TB}$.

\section{Conclusion}

The findings of the current study are consistent with potentially harmful, pro-inflammatory and pro-infective interactions of smoking and pulmonary $\mathrm{TB}$ associated with depletion of leukocyte vitamin C. Although no differences in radiographic indices of disease activity between smokers and non-smokers were evident on presentation, it is conceivable that the interactive pro-inflammatory effect of smoking, which persists beyond completion of chemotherapy, albeit at a lower level ${ }^{7,8}$, may impact negatively on the longer-term pulmonary ${ }^{30}$ and cardiovascu$\operatorname{lar}^{31}$ sequelae of TB.

\section{Acknowledgement}

Charles Feldman is supported by the National Research Foundation (SA).

\section{Conflict of interest}

None of the authors has a conflict of interest to declare.

\section{References}

1. Rao VG, Bhat J, Yadav R, Muniyandi M, Bhondeley MK, Sharada MA, Chadha VK, Wares DF (2014) Tobacco smoking: a major risk factor for pulmonary tuberculosis - evidence from a cross-sectional study in central India. Trans R Soc Trop Med Hyg 108: 474-481.

2. Feldman C, Anderson R (2013) Cigarette smoking and mechanisms of susceptibility to infections of the respiratory tract and other organ systems. J Infect 67:169-184.

3. Yen YF, Yen MY, Lin YS, Lin YP, Shih HC, Li LH, Chou P, Deng DY (2014) Smoking increases risk of recurrence after successful anti-tuberculosis treatment: a 
population-based study. Int J Tuberc Lung Dis 18: 492-498. 4. Mutepe ND, Cockeran R, Steel HC, Theron AJ, Mitchell TJ, Feldman C, Anderson R (2013) Effects of cigarette smoke condensate on pneumococcal biofilm formation and pneumolysin. Eur Respir J 41: 392-395.

5. Mityahara E, Nishie M, Takumi S, Miyanohara H, Nishi J, Yoshiie K, Oda H, Takeuchi M, Komatsu M, Aoyama K, Horiuchi M, Takeuchi T (2011) Environmental mutagens may be implicated in the emergence of drug-resistant microorganisms. FEMS Microbiol Lett 317: 109-116.

6. Alet-G mez MN, Alcaide J, Godoy P, Romero MA, Hernández del Rey I (2005) Clinical and epidemiological aspects of smoking and tuberculosis: a study of 13,038 cases. Int J Tuberc Lung Dis 9: 430-436.

7. Plit ML, Theron AJ, Fickl H, van Rensburg CEJ, Pendel S, Anderson R (1998) Influence of antimicrobial chemotherapy and smoking status on the plasma concentrations of vitamin $C$, vitamin $E, \beta$-carotene, acute phase reactants, iron and lipid peroxides in patients with pulmonary tuberculosis. Int J Tuberc Lung Dis 2: 590-596.

8. Miric D, Katanic R, Miric B, Kisic B, Popovic-Katanic N, Nestorovic V (2013) Changes in vitamin C and oxidative stress status during the treatment of tuberculous meningitis. Int J Tuberc Lung Dis 17: 1495-1500.

9. Jacob RA (1990) Assessment of human vitamin C status. J Nutr 120 Suppl 11: 1480-1485.

10. Taneja NK, Dhingra S, Mittal A, Naresh M, Tyagi JS (2010) Mycobacterium tuberculosis transcriptional adaptation, growth arrest and dormancy phenotype development is triggered by vitamin C. PLoS One 5: e10860.

11. Wang J, Zhou X, Zhang Z, Xu L, Yin X, Yang L, Zhao D (2012) Effect of interaction of vitamin C on macrophage immune response to infection with Mycobacterium bovis. Cell Mol Biol 58 Suppl OL: 1688-1694.

12. Vilchèze C, Hartman T, Weinrick B, Jacobs WR Jr (2013) Mycobacterium tuberculosis is extraordinarily sensitive to killing by a vitamin $\mathrm{C}$-induced Fenton reaction. Nat Commun 4: 1881.

13. Padayatty SJ, Doppman JL, Chang R, Wang Y, Gill J, Papanicolaou DA, Levine M (2007) Human adrenal glands secrete vitamin $C$ in response to adrenocorticotrophic hormone. Am J Clin Nutr 86: 145-149.

14. Hafeiz AA, Issa HA, el-Kammah B, Abdel-Hafez MA, Abdou MA, Abdel-Khalek M, Ramadan SM (1992)

African Health Sciences Vol 17 Issue 2, June, 2017
Plasma catecholamines in pulmonary tuberculosis. Kekekaku 67: 647-652.

15. Bozza VV, D’Attilio L, Mahuad CV, Giri AA, del Rey A, Besedovsky H, Bottasso O, Bay ML (2007) Altered cortisol/DHEA ratio in tuberculosis patients and its relationship with abnormalities in the mycobacterial-driven cytokine production by peripheral blood mononuclear cells. Scand J Immunol 66: 97-103.

16. Santucci N, D’Attilio L, Kovalevski L, Bozza V, Besedovsky H, del Rey A, Bay ML, Bottasso O (2011) A multifaceted analysis of immune-endocrine-metabolic alterations in patients with pulmonary tuberculosis. PLoS One 6: e26363.

17. Opolot JO, Theron AJ, Anderson R, Feldman C (2015) Acute phase proteins and stress hormone responses in patients with newly diagnosed active pulmonary tuberculosis. Lung 193: 13-18.

18. Lynch SR, Berelowitz I, Seftel HC, Miller GB, Krawitz P, Charlton RW, Bothwell TH (1967) Osteoporosis in Johannesburg Bantu males. Its relationship to siderosis and ascorbic acid deficiency. Am J Clin Nutr 20: 799-807. 19. Waweru P, Anderson R, Steel H, Venter WDF, Murdoch D, Feldman C (2013) The prevalence of smoking and the knowledge of smoking hazards and smoking cessation strategies among HIV positive patients in Johannesburg, South Africa. S Afr Med J 103: 858-860.

20. Clark KEN, Brown J, Hopwood JM, Lynard O, Creer D, Barker RD, Smith C, Breen R, Cropley I, Lipman M (2014) C-reactive protein reflects mycobacterial load in active tuberculosis but cannot be used as a rule-out diagnostic test. Thorax 69 Suppl 2: A33 (abstract).

21. Bergsten P, Amitai G, Kehrl J, Dhariwal KR, Klein HG, Levine M (1990) Millimolar concentrations of ascorbic acid in purified human mononuclear leukocytes. J Biol Chem 265: 2584-2587.

22. Wang J, Pantopoulos K (2011) Regulation of cellular iron metabolism. Biochem J 434: 365-381.

23. Mortensen RF (2001) C-reactive protein, inflammation, and innate immunity. Immunol Res 24: 163-176.

24. Suresh MV, Singh SK, Ferguson DA Jr., Agrawal A (2006) Role of the property of C-reactive protein to activate the classical pathway of complement in protecting mice from pneumococcal infection. J Immunol 176: 43694374.

25. Shephard EG, Anderson R, Rosen O, Fridkin M (1992) C-reactive protein (CRP) peptides inactivate eno- 
lase in human neutrophils leading to depletion of intracellular ATP and inhibition of superoxide generation. Immunology 76: 79-85.

26. Mortensen RF, Osmand AP, Gewurz H (1975) Effects of C-reactive protein on the lymphoid system. I. Binding to thymus-dependent lymphocytes and alteration of their functions. $J$ Exp Med 141: 821-839.

27. Maciel EL, Brioschi AP, Peres RL, Guidoni LM, Ribeiro FK, Hadad DJ, Vinhas SA, Zandonade E, Palaci M, Dietze R, Johnson JL (2013) Smoking and 2-month culture conversion during anti-tuberculosis treatment. Int J Tuberc Lung Dis 17: 225-228.

28. Pefura-Yone EW, Kengne AP, Kuaban C (2014)
Non-conversion of sputum culture among patients with smear positive pulmonary tuberculosis in Cameroon: a prospective cohort study. BMC Infect Dis 14: 138.

29. Siddiqui UA, O’Toole M, Kabir Z, Qureshi S, Gibbons N, Kane M, Keane J (2010) Smoking prolongs the infectivity of patients with tuberculosis. Ir Med J 103: 278-280.

30. Pasipanodya JG, Miller TL, Vecino M, Munguia G, Garmon R, Bae S, Drewyer G, Weis SE (2007) Pulmonary impairment after tuberculosis. Chest 131: 1817-1824. 31. Chung WS, Lin CL, HungCT, Chu YH, Sung FC, Kao CH, Yeh JJ (2014) Tuberculosis increases the subsequent risk of acute coronary syndrome: a nationwide population-based cohort study. Int J Tuberc Lung Dis 18: 79-83. 